\title{
Review on Biochemical Detection of Biological, Plant Samples Using Integrative Approach
} \author{
Musawir Hussain ${ }^{1}$, Asifa Ghafoor ${ }^{1}$, Abdul Rauf ${ }^{1}$, Muhammad Zakaullah ${ }^{1}$, Khazra Fiaz ${ }^{1}$, Muhammad Saleem ${ }^{1}$, Mutloob
} Ahmad $^{2}$, Muhammad Shafqat $^{1}$, Hamza Rafeeq ${ }^{3 *}$

${ }^{1}$ Department of Botany, University of agriculture Faisalabad, Pakistan

${ }^{2}$ Department of Botany, Ghazi University, Dera Ghazi Khan, Pakistan

${ }^{3}$ Department of Biochemistry, University of agriculture Faisalabad, Pakistan

DOI: $10.36348 / \mathrm{sb} .2021 . \mathrm{v} 07 \mathrm{i} 03.004$

| Received: 21.01.2021 | Accepted: 04.02.2021 | Published: 18.03.2021

*Corresponding author: Hamza Rafeeq

\section{Abstract}

Biosensor is the system which is generally consists of the system which recognizes the biological samples in appropriate manner. Bio receptor makes interaction with the analytic and transducer help in the amplification of the signals and measureable signals can be displayed on the screen in the form of the electrical signals. Bio-receptor is a biological molecule such as the enzyme, antibody, protein, and nucleic acid which is commonly present in the living organism which is used in the recognition of the biological molecule. Different techniques play as the key role in the technologies for the specificity, for seeking the measurement analyte make interaction with the electrode of the sensor. Biological signal based Biosensor can be categorized as Immuno-biosensor, Enzyme Based biosensor, Nucleic acid /DNA based biosensor and Cellular based biosensor. In the body with the high specificity and the sensitivity the ability of to detect the physiological and the pathogenic related molecules offers a opportunity which is very powerful and helpful in the treatment of the disease with the early diagnosis. The metals such nickel, cobalt which play essential role and act as the catalyst and also stabilize the structure of biological molecule such as the bacterial cell wall and the proteins. The metals in the high concentration cause the toxicity in the blood.

Keywords: Biosensor, Enzymes, metals, amino acids, proteins, baroreceptor.

Copyright (C) 2021 The Author(s): This is an open-access article distributed under the terms of the Creative Commons Attribution 4.0 International License (CC BY-NC 4.0) which permits unrestricted use, distribution, and reproduction in any medium for non-commercial use provided the original author and source are credited.

\section{INTRODUCTION}

The light source is used in the light bio sensor and a beam of light id generated in the various component of the optical biosensors which have specific in characteristics, the light is used in this used as agent of modulating, in the optical bio sensor the head consist of photodetector[1,2]

Different flourescent protein green in color and other AFP auto- fluorescent protein have great impact in the development of the biosensors which is genetically encoded. This kind of the biosensor is very easy to manipulate, transfer into the cell, another kind of the biosensors use Is the example of the FRET biosensor of signal change, and these are consist of the a pair of the AFPs that transfer the energy and the Flouresense, in them and brought them closer, many different methods is use to enhance the FRET which is based on the intensity and lifetime ratio. There are many sensors of the protein and the peptide that can be manufactured through using the synthetic sources of the chemistry and labeling is done by the enzyme fluorescence being the independency of the genetically coded theses are used to utilized the activity of the target and alternative attractive which have benefit to increase the noise to signal ratio and response sensitivity checked through the photochemical and the quencher groups [3-5].

There is no doubt about that Otto Warburg was the inventor of the analysis of enzymatic actions. In the 1930s mid he observed the detection of the NADH and NADPH at wavelength of the $340 \mathrm{~nm}$ that was the very sensitive results of the detection of the different dehydrogenases and their various substrates and this done by using the optical test. Different scientist such as 
Musawir Hussain et al., Sch Bull, Mar, 2021; 7(3): 38-43

Hans and Bergmeyer has developed different commercial enzymes of the optics which is based on the initial Warburg model. Leland $\mathrm{C}$ was the Father of the biosensors he observed that the oxygen is reduced by the using of the different platinum electrode and measure the blood oxygenation and due to the absorbance of the blood on the surface of the electrodes biosensor was got failed which causes the hindrance in the signals. He introduced the new idea of the biosensor development by using the wrapper of the cell phone and the packet of the cigarette. This method was useful only for the low molecular weight atoms such as oxygen which can easily pass from the and can be measured easily [6].
Lateral Flow Microarrays for Plants Detection

Lateral flow microarrays (LFM) allow rapid, hybridization-based nucleic acid detection using an easily visualized colorimetric signal. These arrays are built on miniaturized lateral flow chromatography nitrocellulose membrane, hybridize in minutes, have detection limits similar to microarrays, and can reduce the need for expensive laboratory instruments. The technology depends on the availability of strong and reliable host and pathogen biomarkers discovered through transcriptomic approaches. Highly interactive proteins such as heat shock proteins or dehydrins, upregulated by different environmental factors [7, 8].

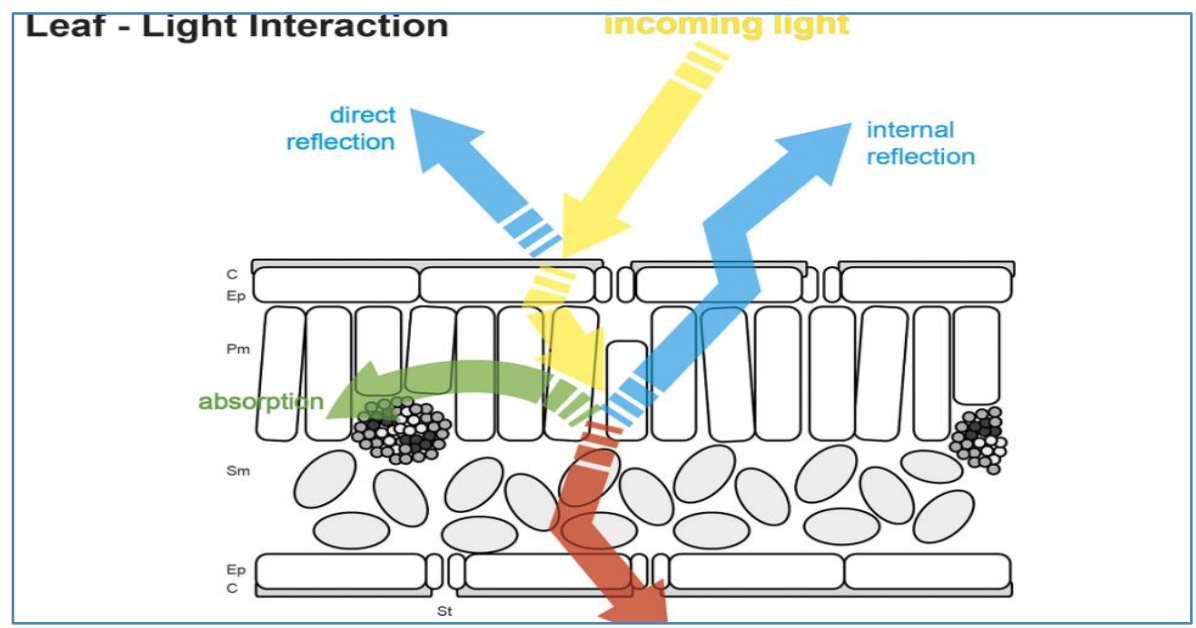

Fig-1: Shows the lateral flow microarrays mechanism in plants

\section{PCR for Plants and Biological samples Detection}

PCR offers several advantages over immunoassays: the capability to detect a single target in complex mixtures, rapid and specific detection of multiple targets, and the potential to detect unculturable pathogens such as viruses or some bacteria and phytoplasma. In addition, costs of analysis are lower than $1 € /$ sample. In PCR-based diagnostics, primers are designed to pair with unique DNA regions from target organisms for DNA amplification and detection. The presence of the amplification product confirms the presence of the organism in the tested sample. The original method of visualizing the amplified product through agarose gel electrophoresis with ethidium bromide (EtBr) staining has been replaced by less toxic and more sensitive SYBR GREEN detection under UV irradiation $[9,10]$.

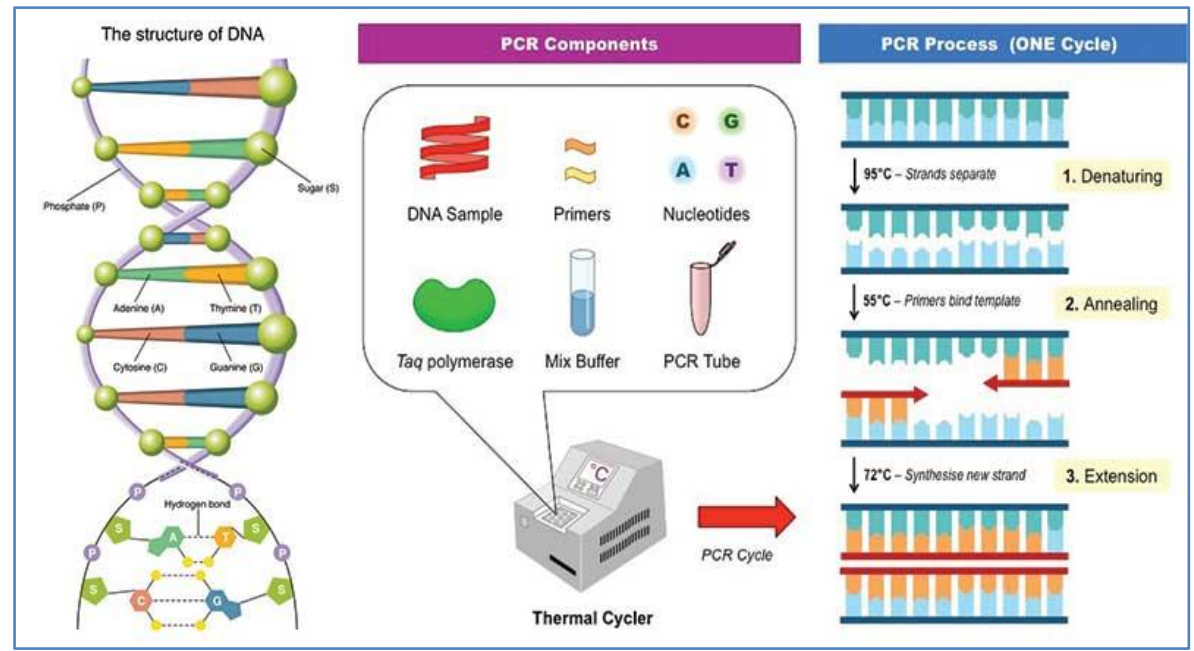

Fig-2: Shows the different essential comments, principle of PCR 


\section{The potential Role of Biosensor System}

The analyte in a sample can easily be electro chemically determine by the help of bio system. In the detection of the analyte the electrode is used and partially hydration of the analyte on the surface of the electrodes make done and the measurement of the current of the electrode is seen. The detection of the analyte is the characteristic of the different concentration of analyte in the different sample and the reaction which is going to take place in very specific in their action which held on the surface of the electrodes and electron is transfer through the electrode layer which give the different curve for the time and the concentration and then evaluation is performed on the basis of graph and the algorith. The invention of this technique done for the determination of the electrochemical analyte in the sample of fluid which is biological in nature and these system is termed as the bio sensor system or the biosensors[6-9].

\section{Plant Disease Detection by Imaging Sensors}

Spectral sensors are generally categorized based on the spectral resolution (i.e., the number and width of measured wavebands), on their spatial scale, and on the type of detector, (i.e., imaging or nonimaging sensor systems). Multispectral sensors were the first spectral sensors invented. These sensors typically assess the spectral information of objects in several relatively broad wavebands. Multispectral imaging cameras may provide data, for instance, in the R, G, and B wavebands and in an additional nearinfrared band. The evolution of modern hyperspectral

sensors increased the complexity of the measured data by a spectral range of up to 350 to $2,500[10,11]$.

\section{Biosensors for Biological Samples Detection}

The maximum use in clinical there are many potential limitations of these techniques for example some of the techniques which are very slow in their action and are difficult for the patients. But the assays use in these techniques are very cost expensive and for the pateints that may be for the industries in every year billions of he dollars and so these are the condition to develop the cheapest and the reliable product which are really in approach to the every single patient which is helpful in the detection and the sensing techniques [69].

\section{Role of Bioreceptors}

In the past decades human beings start to analyze the biological molecule, by using various kind cell of nerve which is obtained from the nose and use in the sense the different scents and the reaction of the enzyme taking place on the tongue to check the food taste. With the passage of time developmental progress in the field of technology and the level of perception to understand about the living organism and their complexity and the different chemical composition present with in the living organism can be measured. A system is discovering which is having the high specificity and the selectivity for the biological analyte. To detect the analyte from the sample of the biological fluids which transduce the signals and convert into the measureable signals use in the various kind of technologies such as the biochips and biosensors [10$12]$.

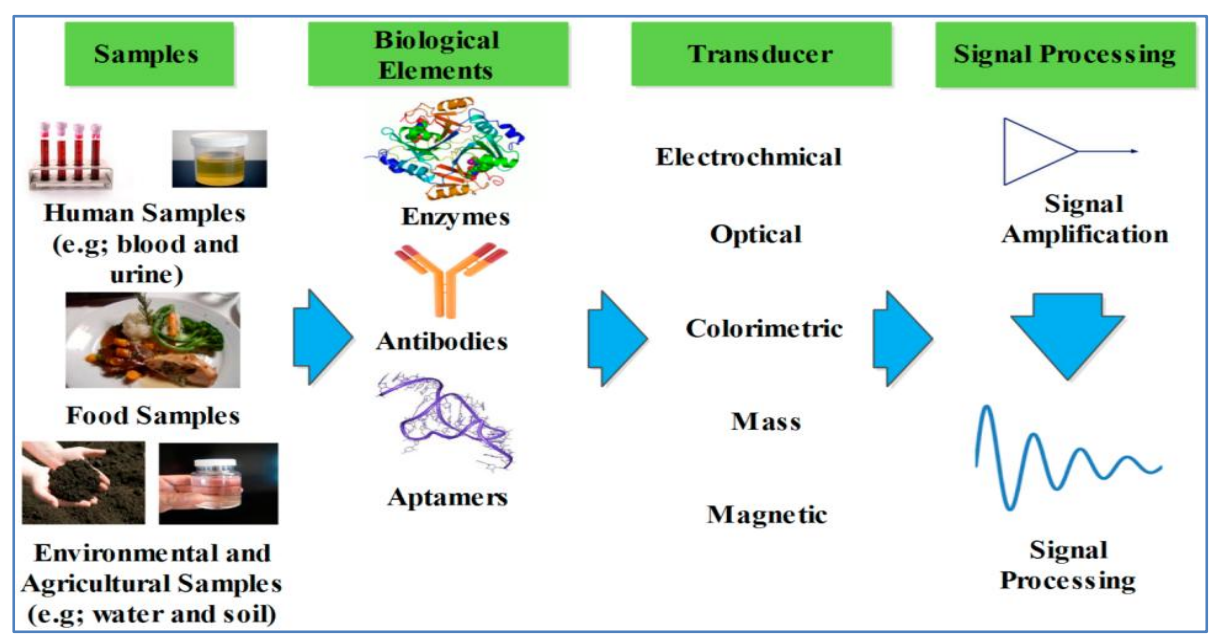

Fig-3: Shows the components and principle of biosensors

\section{Immuno-biosensor}

In the very first in 1950s the biosensor of the antibody was firstly applied for the different kind detection of different diagnosis of immune molecules from the 1950s an immune bio sensor which work on the base of antigen antibody interaction and also a bio receptor and many efforts has been done for the to develop the bio sensor which work on the principle of the antigen antibody base interaction. The immuneglobulins are present in the form of the $\mathrm{Y}$ shaped which is commonly name as the (IG), and the antibody consist of the 2 heavy and 2 light chains which is denoted with the $\mathrm{H}$ and L. Mostly the dimeric is formed with in the human antibody, also pentameric structure is present in 
which disulfide bond is present furthermore another type of protein the present which act a joining of the two chains called J- Chain[13-15].

Now a days in the field of immune sensor there are only two type of biosensors which is electrochemical and the optical, nut the optical biosensor show the less sensitivity as compared to the electrochemical biosensors when this is used along the radio immune biosensor. The radioactive element which have the different half-life and much of the concern related to the health and the hazards of the human any many other problems related to the disposals. The problem is sought out by the help of the electrochemical detector that is related to the other kind of detectors of the immune assays and the immune bio sensors. On the other hand electrochemical detectors which have very minute problems, less economic, simple and the fast type of immune bio sensor[16,17].

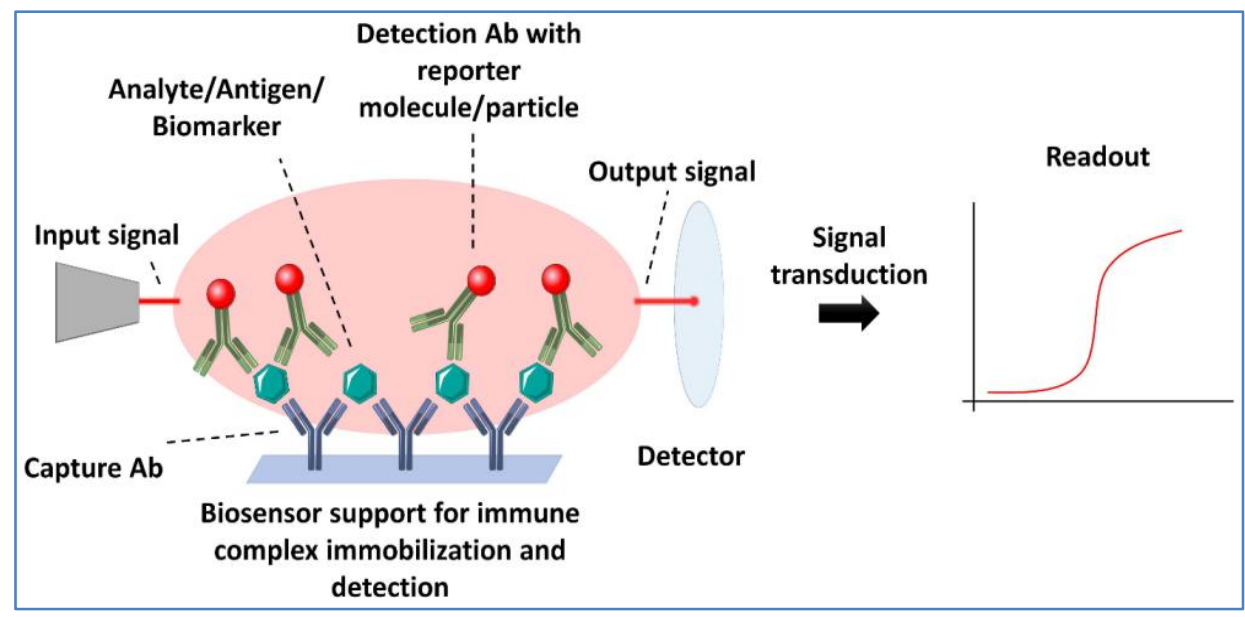

Fig-4: Shows the components and principle of immunobiosensor

\section{Spectrophotometer based detection}

A spectrophotometer is an instrument that measures the amount of light absorbed by a sample. Spectrophotometer techniques are mostly used to measure the concentration of solutes in solution by measuring the amount of the light that is absorbed by the solution in a cuvette placed in the spectrophotometer. There are two major classes of devices: single beam and double beam. A double beam spectrophotometer [13] compares the light intensity between two light paths, one path containing a reference sample and the other the test sample [18, 19].
A single-beam spectrophotometer measures the relative light intensity of the beam before and after a test sample is inserted. Although comparison measurements from double-beam instruments are easier and more stable, single-beam instruments can have a larger dynamic range and are optically simpler and more compact. Additionally, some specialized instruments, such as spectrophotometers built onto microscopes or telescopes, are single-beam instruments due to practicality [14].

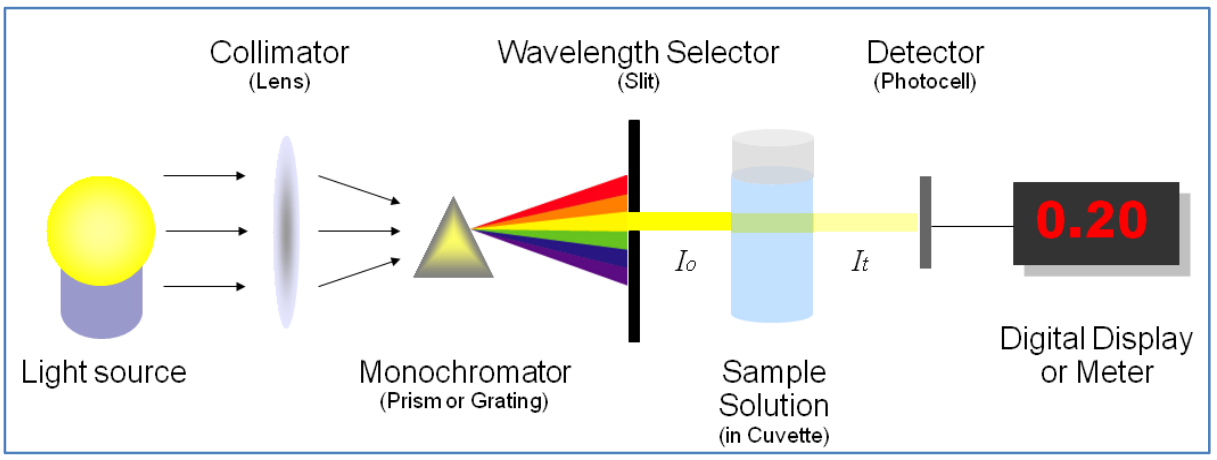

Fig-5: Shows the components and principle of Biosensor

\section{Fluorescence based}

As the electron when present in the higher orbital and goes to the ground state orbital they emit radiation and some of the atoms when they goes from their exited to their relax state[20-22]. And the every single atom emit different type of radiations from their source of energy and goes to their stage which is really in exited form, and the electromagnetic radiation can be supplied through the some kind of the radiation elements such as the luminescence by the photo and by 
heat, and different type of frictional force and impact of the electron such as the luminescence by the cathodes and by the crystallization of the different elements [2325]. For the production of the light the external source is required which has the short wavelength by which the initial electronic transition atom and the molecule and then produced luminescence which is having the long wavelength $[26,27]$. In the recognition of the biological molecule the flurochrome is used which is used to produce the light in the sample. Some of the molecules which does not have the spectral properties in the fluorescence based transducer the dye is used in the sample which attached with the recognize element and when the chemical reaction take place in the sample they emit light which can be measured with the help of the transducer[28, 29].

In the types of the biosensor many types of the biosensor had been develop for the compound determination belong to or relevance with the environment such as the aromatic amine and the phenols metal and the pesticides there is long ago to determine the complete information about the biosensors. In the biosensor the interaction between the biological molecules take place that may be kid of enzyme and the receptors which is really dangerous for the health. The heavy metals which are highly stabilized make the complex of the metals cannot be recognized by the biological molecule are really harmed for the living organism and mostly bound are present [30, 31].

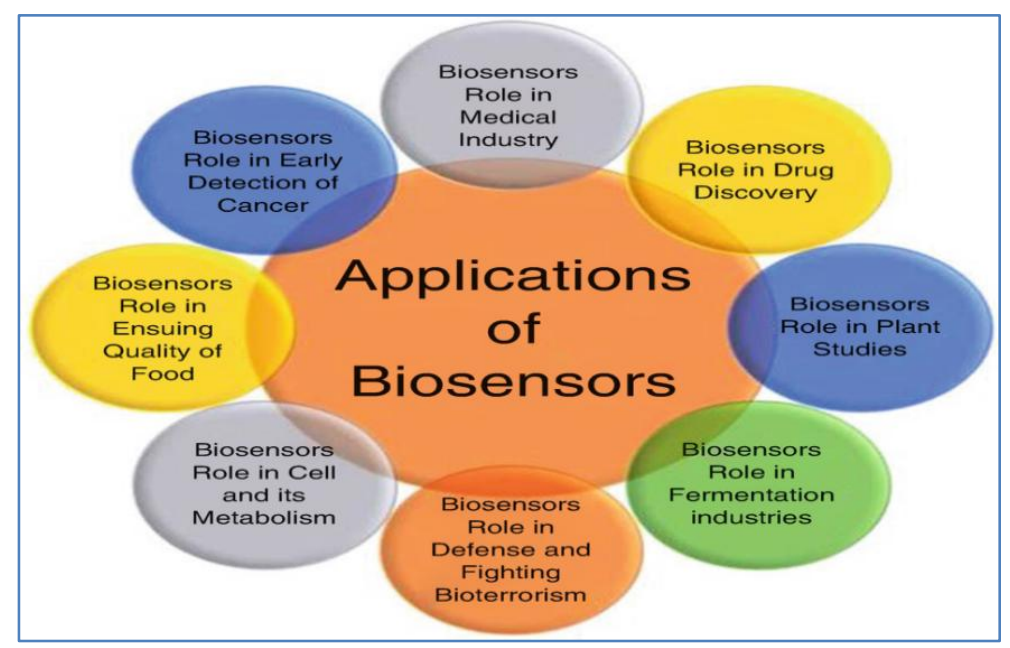

Fig-6: Shows the potential role and applications of biosensors

\section{CONCLUSION}

In past decades the advancement in the field of bio sensor and the bio technologies which have great impact in the life style of the human being in many ways .The biosensor tool which is used in the fields of area of a good life such as research related to medicine, public health-care, in the monitoring of the environment, now a days scientist make more advancement In the field of technologies and promising the rapid detection of the analyte with in the low cost moreover there are many studies which reveal that measurement can be taken with the help of the simple buffer solution instead of the complex composition of the solution.

\section{REFERENCES}

1. Shahid, A., Ali, S., Zahra, T., Raza, M., Shahid, A., Saeed, M. U., \& Javaid, F. Influence of Microbes in Progression of Cancer and DNA Damaging Effects.

2. Iftikhar, A., Shahid, A., Shah, S. S., Ali, S., Raza, M., Ali, E., \& Umbreen, S. Antimicrobial Activities of Selected Medicinal Plant with Potential Role of Chemical Compounds.
3. Qamar, M., Mustafa, G. A., Tariq, S., Rafeeq, H., Rafiq, M., Naqvi, W. Z., \& Kanwal, T. Novel Methods for Detection of Biological Samples, Current Direction and Future Perspectives.

4. Caspi, R., Billington, R., Keseler, I. M., Kothari, A., Krummenacker, M., Midford, P. E., \& Karp, P. D. (2020). The MetaCyc database of metabolic pathways and enzymes-a 2019 update. Nucleic acids research, 48(D1), D445-D453.

5. Naeem, M., Hayat, M., Qamar, S. A., Mehmood, T., Munir, A., Ahmad, G., \& Hussain, A. (2019). Risk factors, genetic mutations and prevention of breast cancer. Int. J. Biosci, 14(4), 492-496.

6. Shafiq, S., Adeel, M., Raza, H., Iqbal, R., Ahmad, Z., Naeem, M., \& Azmi, U. R. (2019). Effects of Foliar Application of Selenium in Maize (Zea Mays L.) under Cadmium Toxicity. In Biological Forum-An International Journal (Vol. 11, No. 2, pp. 27-37).

7. Ahmad, I., Khan, S., Naeem, M., Hayat, M., Azmi, U. R., Ahmed, S., \& Irfan, M. (2019). Molecular Identification of Ten Palm Species using DNA Fingerprinting. Int. J. Pure App. Biosci, 7(1), 4651. 
Musawir Hussain et al., Sch Bull, Mar, 2021; 7(3): 38-43

8. Usman, G., Muhammad, N., Hamza, R., Usman, I., Ayesha, A., Saqib, U., \& Fatima, Q. (2019). A Novel Approach towards Nutraceuticals and Biomedical Applications. Scholars International Journal of Biochemistry, 2(10), 245-252.

9. Tahir, M. F., Ali, S., Noman, M., \& Goher, M. (2020). A Novel Approach towards the Potential Effects of Chlorpyrifos on Testicular Biochemistry and Physiology of Male Sprague Dawely Rats.

10. Naeem, M., Ali, J., Hassan, M. Z., Arshad, B., Rao, M. H. I., Sarmad, M. S. K., \&amp; Hassan, M. U. (2019). Novel Approach towards DNA Barcoding as a Tool in Molecular Biologyand Biological Activities of Cyclotides with Particular Emphasizes at Molecular Level. In Biological Forum-An International Journal, 11(2), 83-96.

11. Zhang, J., Chai, X., He, X. P., Kim, H. J., Yoon, J., \& Tian, H. (2019). Fluorogenic probes for diseaserelevant enzymes. Chemical Society Reviews, 48(2), 683-722.

12. He, J., Chen, Q., Xin, P., Yuan, J., Ma, Y., Wang, X., \& Wang, G. (2019). CYP72A enzymes catalyse 13-hydrolyzation of gibberellins. Nature plants, 5(10), 1057-1065.

13. Naeem, A., Saddique, S., \& Chand, S. A. (2019). Advancement and Future Directions towards Herbal Treatment for Various Diseases.

14. Basso, A., \& Serban, S. (2019). Industrial applications of immobilized enzymes-A review. Molecular Catalysis, 479, 110607.

15. Drout, R. J., Robison, L., \& Farha, O. K. (2019). Catalytic applications of enzymes encapsulated in metal-organic frameworks. Coordination Chemistry Reviews, 381, 151-160.

16. Naeem, M., Ashraf, A., Safdar, H. M. Z., Khan, M. Q., Rehman, S. U., Iqbal, R., \& Ahmad, G. (2020). Biochemical changes in patients with chronic kidney failure in relation to complete blood count and anemia. IJB, 16(1), 267-271

17. Liu, J. J., Orlova, N., Oakes, B. L., Ma, E., Spinner, H. B., Baney, K. L., ... \& Doudna, J. A. (2019). CasX enzymes comprise a distinct family of RNAguided genome editors. Nature, 566(7743), 218223.

18. Naeem, M., Hussain, A., Azmi, U. R., Maqsood, S., Imtiaz, U., Ali, H., \& Ghani, U. (2019). Comparative Anatomical Studies of Epidermis with Different Stomatal Patterns in Some Selected Plants Using Compound Light Microscopy. International Journal of Scientific and Research Publications, 9(10), 375-380.

19. Ahsan, M., Aslam, M., Akhtar, M. A., Azmi, U. R., Naeem, M., Murtaza, G., \& Shafiq, S. (2019). Effect of inoculation of three rhizobial strains on maize hybrids. Journal of Biodiversity and Environmental Sciences, 14(6), 168-177.
20. Hazafa, A., Batool, A., Ahmad, S., Amjad, M., Chaudhry, S. N., Asad, J., \& Ghani, U. (2020). Humanin: A mitochondrial-derived peptide in the treatment of apoptosis-related diseases. Life Sciences, Volume 264, 2021, 118679.

21. Khan, S., Abbas, A., Ali, I., Arshad, R., Tareen, M. B. K., \& Shah, M. I. (2019). Prevalence of overweight and obesity and lifestyle assessment among school-going children of Multan, Pakistan.

22. Rafeeq, H., Ahmad, S., Tareen, M. B. K., Shahzad, K. A., Bashir, A., Jabeen, R., ... \& Shehzadi, I. (2020). Biochemistry of Fat Soluble Vitamins, Sources, Biochemical Functions and Toxicity.

23. Ghani, U., Naeem, M. Bukhari, S.S.H., Yar, G., Tariq, I., Siddique, S., Nawaz, H.A., Pal, Z.A.A., Nasim, F. and Bukhari, S.A.H. (2019). Prevalence and Risk Factors associated with Hepatitis B and Hepatitis $\mathrm{C}$ and their Correlation with Inflammatory Markers among Southern Region of Punjab. Biological Forum - An International Journal, 11(2): 136-143.

24. Khan, S., Zelle Rubab, S. H., Abbas, A., Arshad, R., \& Tareen, M. B. K. Hematological profile of children with severe acute malnutrition at the Tertiary care hospital in Multan.

25. Copeland, R. A., \& Retey, J. (1996). Enzymes: a practical introduction to structure, mechanism, and data analysis (pp. 195-197). New York: VCH Publishers.

26. Muhammad, N., Umair, R.A., Sarmad, A. Q., Ahmad, M., Tariq, M., Muhammad, A.F. (2019). Reliable vaccine production by using Risk Based Bioengineering Strategies. 6th International Conference on "Sustainable Agriculture in Changing Climate: Strategies and Management, 261.

27. Einsle, O., \& Rees, D. C. (2020). Structural Enzymology of Nitrogenase Enzymes. Chemical Reviews, 120(12), 4969-5004.

28. Zhang, X., Ward, B. B., \& Sigman, D. M. (2020). Global nitrogen cycle: critical enzymes, organisms, and processes for nitrogen budgets and dynamics. Chemical Reviews, 120(12), 5308-5351.

29. Bugg, T. D., Williamson, J. J., \& Rashid, G. M. (2020). Bacterial enzymes for lignin depolymerisation: new biocatalysts for generation of renewable chemicals from biomass. Current Opinion in Chemical Biology, 55, 26-33.

30. Gómez, J., Albaiceta, G. M., García-Clemente, M., López-Larrea, C., Amado-Rodríguez, L., LopezAlonso, I., \& Coto, E. (2020). Angiotensinconverting enzymes (ACE, ACE2) gene variants and COVID-19 outcome. Gene, 762, 145102.

31. Liu, Y. S., \& Fujita, M. (2020). Mammalian GPIanchor modifications and the enzymes involved. Biochemical Society Transactions, 48(3), 1129-1138. 